\title{
Measuring body composition using the bioelectrical impedance method can predict the outcomes of gemcitabine-based chemotherapy in patients with pancreatobiliary tract cancer
}

\author{
MAMI MURAMATSU ${ }^{1,2}$, AYA TSUCHIYA ${ }^{1,2}$, SEIKO OHTA $^{1,2}$, YUKIE IIJIMA $^{1,2}$, MIYUKI MARUYAMA $^{1,2}$, \\ YOSHIKO ONODERA ${ }^{2}$, MEGUMI HAGIHARA ${ }^{2}$, NAOKI NAKAYA ${ }^{1}$, ITARU SATO ${ }^{1}$, \\ KENJI OMURA ${ }^{1}$, SOICHIRO UENO $^{1}$ and HIDEO NAKAJIMA ${ }^{1,3}$
}

${ }^{1}$ Department of Oncology and ${ }^{2}$ Chemotherapy Unit for Outpatients, Ageo Central General Hospital, Ageo, Saitama 362-8588;
${ }^{3}$ Department of Surgery, Saitama Medical Center, Saitama Medical University, Kawagoe, Saitama 350-8550, Japan

Received November 3, 2014; Accepted September 17, 2015

DOI: 10.3892/ol.2015.3811

\begin{abstract}
In order to examine the effect on body composition of anticancer drug treatments, the body composition rate in patients being treated with gemcitabine (GEM)-based chemotherapy was measured over time on an outpatient basis with a simple body composition monitor using the bioelectrical impedance (BI) method. The results revealed a significant reduction in the body fat rate $(\mathrm{P}=0.01)$ over the course of treatment in patients with pancreatobiliary tract cancer who became unable to continue GEM-based chemotherapy due to progressive disease or a decreased performance status. Meanwhile, no changes were observed in the body composition of control patients with urothelial carcinoma receiving GEM-based chemotherapy. In association with the adverse reactions to GEM and the hematotoxicity profile, a decreased white blood cell count was more likely to occur in body fat-dominant patients (mean fat rate, $25.8 \%$; mean muscle rate, $26.2 \%$ ), whereas a decreased blood platelet count was more likely to occur in skeletal muscle-dominant patients (mean fat rate, $23.3 \%$; mean muscle rates, $28.7 \%$ ). The correlation between body composition parameters and the relative dose intensity (RDI) associated with GEM administration was also analyzed. The results revealed a positive correlation between the RDI and basal metabolism amount $(\mathrm{P}=0.03)$; however, the RDI did not correlate with the body fat rate, skeletal muscle rate or body mass index $(\mathrm{P}=0.61, \mathrm{P}=0.14$ and $\mathrm{P}=0.20$, respectively).
\end{abstract}

Correspondence to: Dr Hideo Nakajima, Department of Oncology, Ageo Central General Hospital, 1-10-10 Kashiwaza, Ageo, Saitama 362-8588, Japan

E-mail: nakajima.h@ach.or.jp

Abbreviations: BI, bioelectrical impedance; BMI, body mass index; GEM, gemcitabine; PS, performance status; PD, progressive disease; RDI, relative dose intensity

Key words: body composition, bioelectrical impedance method, gemcitabine, chemotherapy, pancreatobiliary tract cancer
In conclusion, the body composition rate measurement using the BI method over time may be useful for predicting the outcome of GEM-based chemotherapy and adverse events in patients with pancreatobiliary tract cancer. In particular, the present findings indicate that the changes in body fat rate may be helpful as an adjunct index for assessing potential continuation of chemotherapy and changes in physical conditions.

\section{Introduction}

Advanced pancreatobiliary tract cancer has a poor prognosis, despite recent advances in systemic treatments. Although gemcitabine (GEM) has been the reference regimen, demonstrating a clinical benefit and prolonging survival, survival times remain short (1). More intensive and combined chemotherapy regimens with platinum agents (e.g., cisplatin or oxaliplatin), erlotinib or nab-paclitaxel have been developed and represent an area of great interest; however, it remains difficult to achieve $>1$-year survival, and intensive side effect management is required (2-4). Compared with pancreatobiliary tract cancer, urothelial carcinoma is slightly less aggressive and more chemosensitive, and the GEM/cisplatin (GC) regimen is generally considered to be the current standard care for metastatic cases, replacing the methotrexate/ vinblastin/doxorubicin/cisplatin regimen (5). Thus, GEM is a key drug in the chemotherapeutic treatment of pancreatobiliary tract and urothelial carcinoma, and may be used alone or in combination with other anticancer drugs. Its dose is practically determined based on the patient's body surface area, and is adjusted according to patient age, hematological data, adverse events, and other factors (6-8). However, when determining its administration or doses, there are few useful adjunct indices that may be used easily and non-invasively to understand the patient's condition and to predict changes in their pathological state.

The importance of body composition measurement in the clinical setting has been increasing in recent years. The prevalence of obesity has become a public health problem, in association with cardiovascular disease, throughout the world, particularly in developed countries. Loss of skeletal muscle 
Table I. Characteristics of patients $(\mathrm{n}=37)$.

\begin{tabular}{lcccc}
\hline Cancer type & Patients, $\mathrm{n}$ & Treatment regimens & $\begin{array}{c}\text { Age, years; } \\
\text { mean (range) }\end{array}$ & $\begin{array}{c}\text { BMI at treatment initiation, } \\
\mathrm{kg} / \mathrm{m}^{2} ; \text { mean (range) }\end{array}$ \\
\hline $\begin{array}{l}\text { Pancreatic cancer } \\
\text { Female }\end{array}$ & 16 & GEM $(\mathrm{n}=15)$; GEM/S-1 $(\mathrm{n}=1)$ & & \\
$\quad$ Male & 10 & & $69.3(50-82)$ & $19.7(18.6-24.4)$ \\
Biliary cancer & 6 & & $63.5(47-76)$ & $20.7(18.4-22.7)$ \\
Female & 10 & GEM $(\mathrm{n}=9)$; GEM/CDDP $(\mathrm{n}=1)$ & & \\
Male & 2 & & $71.0(67-75)$ & $19.5(17.3-21.6)$ \\
Urothelial cancer & 8 & & $67.7(62-83)$ & $21.4(15.6-25.7)$ \\
Female & 11 & GEM $(\mathrm{n}=4) ;$ CBDCA/GEM $(\mathrm{n}=7)$ & & \\
Male & 2 & & $69.4(60-79)$ & $25.8(25.3-26.2)$ \\
\hline
\end{tabular}

BMI, body mass index; GEM, gemcitabine; CDDP, cisplatin; CBDCA, carboplatin.

mass is associated with impaired mobility and lower quality of life (9). Magnetic resonance imaging (MRI) is considered to be the most precise and reliable method for measuring skeletal muscle in vivo (10), whilst the adipose tissue distribution is commonly evaluated by computed tomography (CT) or MRI $(11,12)$. However, there is emerging interest in the use of bioelectrical impedance (BI) analysis to assess body fat and skeletal muscle mass, and numerous studies have developed equations for estimating body compositions using the BI method (13-15). The principle of BI analysis is based upon the greater electrolyte content of fat-free mass and its greater conductivity of electricity compared with that of adipose tissue or bone. The majority of the BI current flows through skeletal muscle as this has a large volume and a low resistance (16). BI is now becoming more widely used as simple, safe and inexpensive method for estimating body composition. However, as the BI method was developed primarily by analyzing healthy subjects, applying it to a patient care is not sufficiently understood at present.

Therefore, the current study retrospectively analyzed the body composition rates measured over time in patients who were being treated with GEM-based chemotherapy on an outpatient basis.

\section{Patients and methods}

Patients. The study subjects were 37 patients (26 with pancreatobiliary tract cancer and 11 with urothelial carcinoma) who were treated with GEM-based chemotherapy at the Chemotherapy Unit for Outpatients of Ageo Central General Hospital (Ageo, Japan) between November 2012 and April 2014. All outpatients who were eligible to receive GEM-based chemotherapy were included in the study. Standardized inclusion criteria for chemotherapy in the outpatient unit were an Eastern Cooperative Oncology Group (ECOG) performance status score of 0,1 or 2 (17) and adequate bone marrow, liver and renal function (white blood cell count, $\geq 2,000 / \mathrm{mm}^{3}$; platelet count, $\geq 70,000 / \mathrm{mm}^{3}$; bilirubin, $\leq 3.0 \mathrm{mg} / \mathrm{dl}$; aspartate transaminase/alanine aminotransferase, $\leq 150 \mathrm{IU} / \mathrm{l}$; and creatinine, $\leq 1.5 \mathrm{mg} / \mathrm{dl}$ ). Patient characteristics are summarized in Table I. This study was conducted after obtaining informed consent from all the patients, and with approval from the ethics committee of Ageo Central General Hospital.

Measurement of the body composition rate. At each visit for chemotherapy, the total weight $(\mathrm{kg})$, body fat rate $(\%)$, skeletal muscle rate (\%), body mass index (BMI), and basal metabolism of the subjects were measured as body composition parameters using a BI method-based body weight/body composition monitor (Karada Scan HBF-375; Omron Corporation, Kyoto, Japan). When using this measurement method, an electric microcurrent was applied with the patient in a standing position, between the hands and feet to the whole body, including the abdomen; measurements were obtained by subtracting the impedance value between both hands from the impedance value of the whole body $(18,19)$. Following the acquisition of these values, the measurement was calculated by factoring in the height, weight, age, gender and basic physical data of the patients; Omron (http://www.omron. com/) has used research information from several hundred subjects using the hydrodensitometry method to develop the formulas by which the Omron composition monitor calculates the various body composition rates (19-28). In the current study, a retrospective analysis was conducted of the associations between the measurement results (i.e., the aforementioned body composition parameters) and various other factors, including the following: Relative dose intensity (RDI; dose intensity / planned dose intensity x 100) of the GEM; adverse events [according to Common Terminology Criteria for Adverse Events (CTCAE) version 4.03; U.S. Department of Health and Human Service, National Institutes of Health and National Cancer Institute]; ECOG performance status (PS); and progression of the pathological conditions in the subjects evaluated by Response Evaluation Criteria in Solid Tumors guidelines, version 1.1 (29).

Statistical analysis. Microsoft Excel with the Statcel Add-in, 2nd Edition (OMS publishing Inc., Saitama, Japan) was used as the analytical software (30). The association between RDI and body composition was tested using a Pearson's correlation coefficient test; body composition rates and adverse 
A
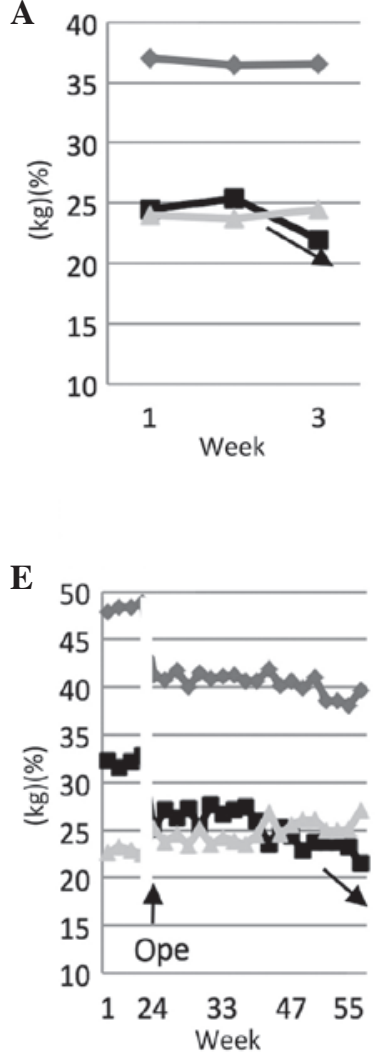

I

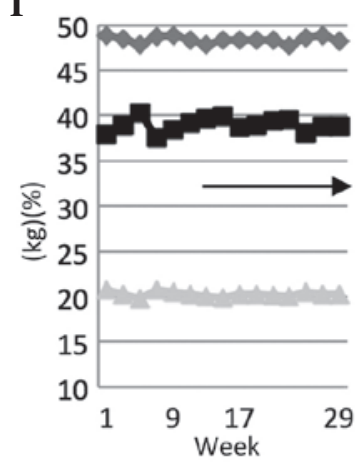

B
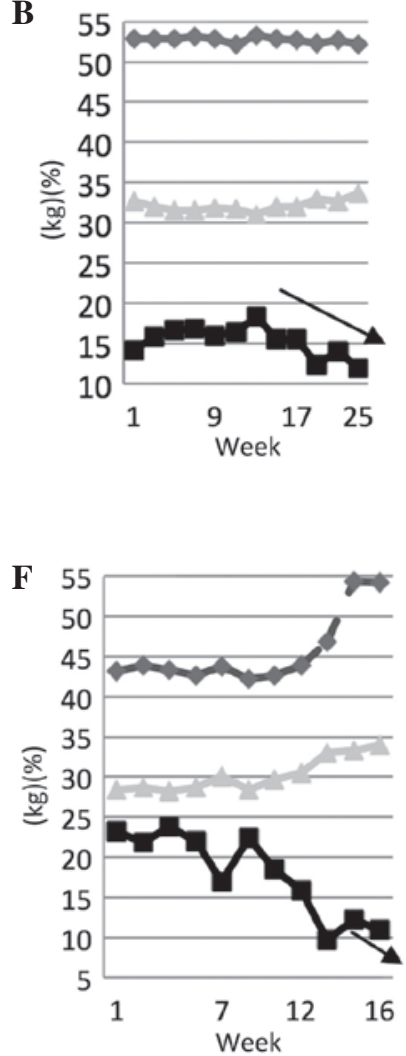

J

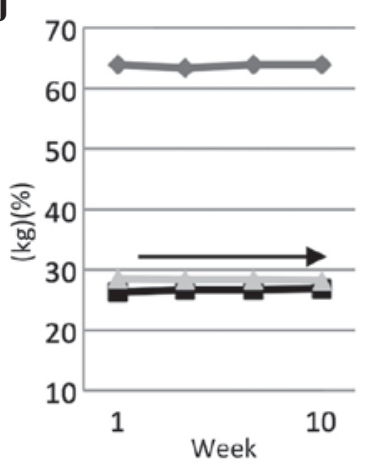

C

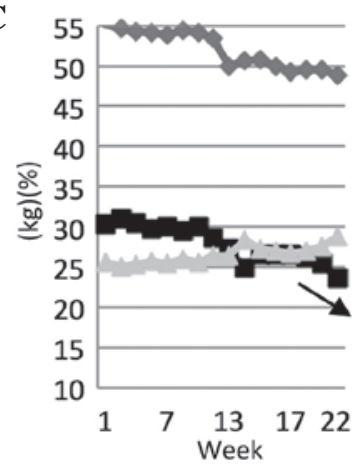

G

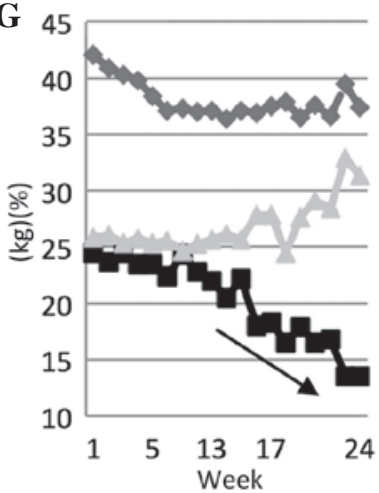

K

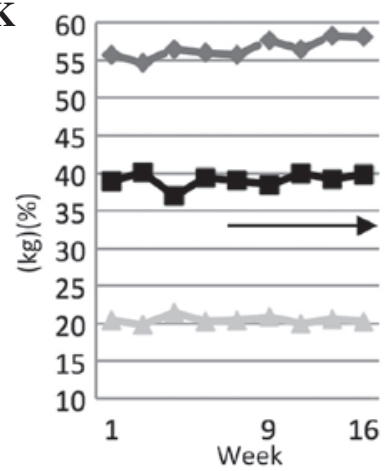

D

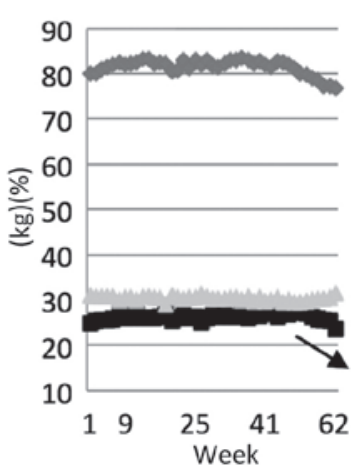

H

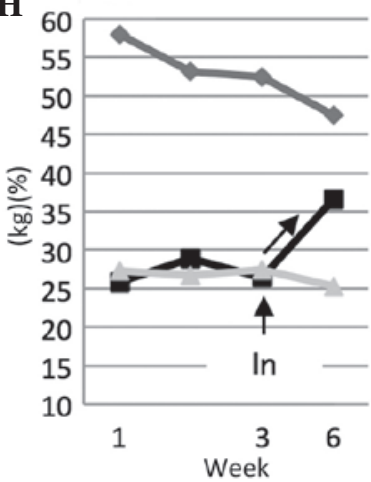

$\longleftrightarrow$ Body weight (kg)

- Body fat rate (\%)

Skeletal muscle rate (\%)

Figure 1. Changes in body composition over time and course of treatment. The values of the vertical axis represent the subject's body weight, skeletal muscle rate (\%), and body fat rate (\%), and the horizontal axis treatment indicates time elapsed (weeks). Arrows indicate changes in the body fat rate. (A) 83-year-old male patient with biliary cancer; treatment was discontinued due to severe adverse events and decreased PS. (B) Male patient, aged 64 years, with pancreatic cancer; the patient was receiving adjuvant chemotherapy, but treatment was discontinued due to PD (lymph node metastasis). (C) Female patient, aged 72 years, with pancreatic cancer who received preoperative chemotherapy; the patient underwent exploratory laparotomy and continued to receive chemotherapy, but treatment was discontinued due to PD (locally advanced disease). (D) 60-year-old male patient with biliary cancer; the patient received GEM 46 times, but the treatment was discontinued due to PD (locally advanced disease). (E) Female patient, aged 74 years, with pancreatic cancer who underwent preoperative chemotherapy followed by pancreaticoduodenectomy (Ope); the patient received adjuvant chemotherapy postoperatively, but the treatment was discontinued due to PD (peritonitis and ascites retention). (F) Male patient, aged 68 years, with biliary cancer; treatment was discontinued due to PD (peritonitis and ascites retention). (G) 70-year-old female patient with pancreatic cancer; treatment was discontinued due to PD (peritonitis and ascites retention). (H) Male patient, aged 64 years, with pancreatic cancer who exhibited onset of jaundice during the treatment and underwent placement of a drainage stent (In); after the jaundice reduced, the patient's PS improved and the continuation of treatment became possible. (I) 67-year-old female patient with pancreatic cancer; the patient underwent postoperative chemotherapy, and the treatment was completed following confirmation of the disappearance of the remaining lesion. (J) Female patient, aged 60 years, with urothelial carcinoma; treatment was discontinued due to PD (brain metastasis). (K) 64-year-old male patient with urothelial carcinoma; treatment was discontinued due to PD (bone and lung metastases) and a decreased PS. PS, performance status; PD, progressive disease.

events were tested using a repeated measures two-way analysis of variance, and changes in body composition and in pathological conditions were tested with cross analysis and comparative tests. $\mathrm{P}<0.05$ was considered to indicate statistically significant differences in all tests.

\section{Results}

Patient characteristics. Of 26 patients with pancreatobiliary tract cancer, 10 were able to receive long-term ( $>6$ months) GEM-based chemotherapy, and 11 received adjuvant 
A

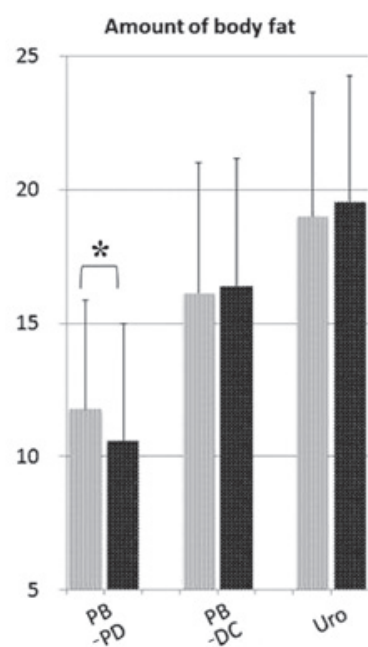

B

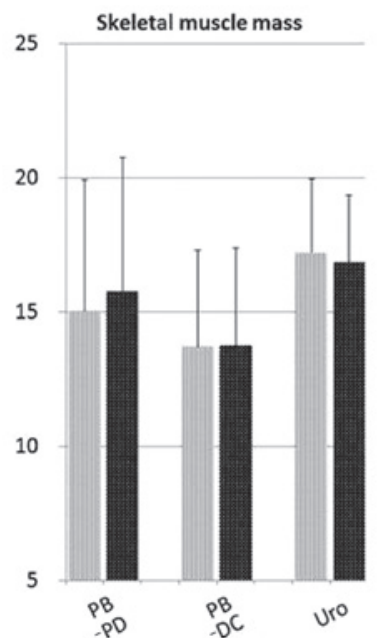

C

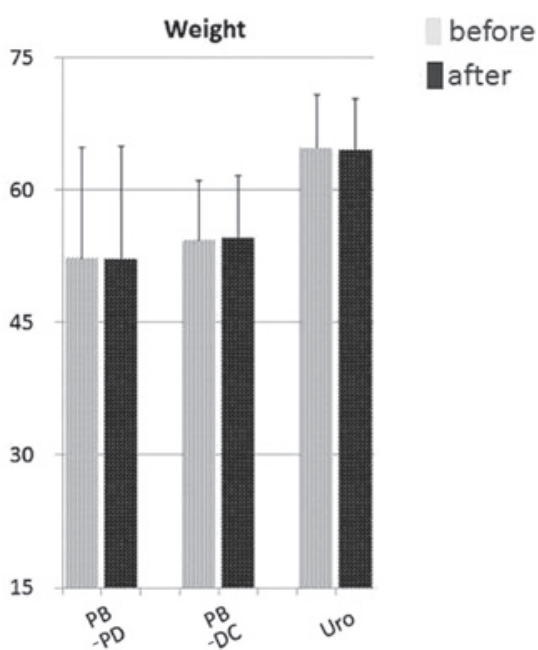

Figure 2. Changes in body composition before and after treatment. The subjects were classified into three groups: Disease control (non-PD+complete response) patients with pancreatobiliary tract cancer (PB-DC; $n=7)$; patients with pancreatobiliary tract cancer with PD (PB-PD; $n=19)$; and patients with urothelial carcinoma (Uro; $n=11$ ). The graphs are plotted for mean values of (A) body fat amount, (B) skeletal muscle mass, and (C) body weight of each group at the first treatment (before) and the end of treatment (after). The $t$-test revealed a significant change in the amount of body fat in $\mathrm{PB}-\mathrm{PD}$ patients $\left({ }^{*} \mathrm{P}=0.01\right)$. $\mathrm{PD}$, progressive disease; DC, disease control.

A

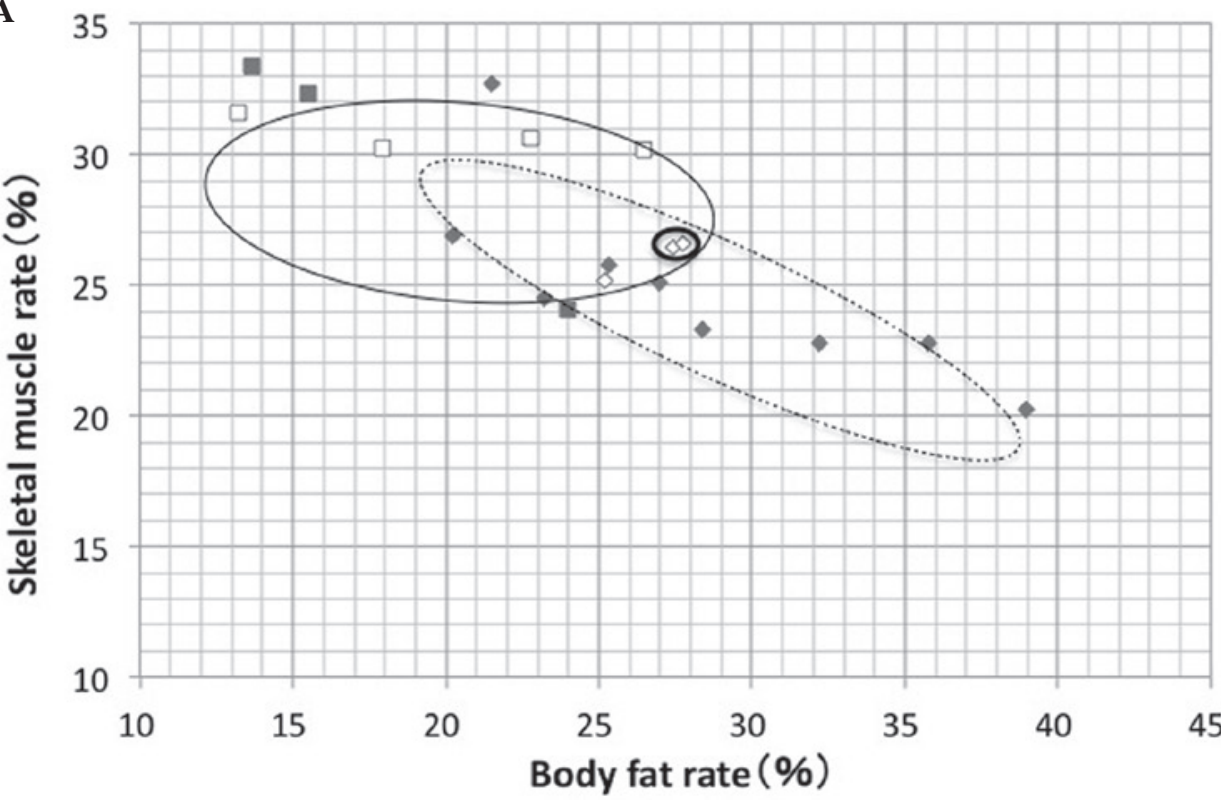

$\checkmark$ Decreased WBC count - female

Decreased WBC count - male

$\triangle$ Decreased PLT count - female

$\square$ Decreased PLT count - male

B

\begin{tabular}{|c|c|c|c|c|}
\hline & $\begin{array}{c}\text { BMI } \\
\left(\mathrm{kg} / \mathrm{m}^{2}\right)\end{array}$ & $\begin{array}{c}\text { Body fat } \\
\text { rate } \\
(\%)\end{array}$ & $\begin{array}{c}\text { Skeletal } \\
\text { muscle } \\
\text { rate (\%) }\end{array}$ & Hematotoxicity \\
\hline Preoperative & 24.1 & 32.2 & 22.8 & $\begin{array}{c}\text { WBC (Gr 2) } \\
\text { PLT (Gr 1) }\end{array}$ \\
\hline Postoperative & 20.6 & 25.2 & 25.2 & $\begin{array}{c}\text { WBC (Gr 1) } \\
\text { PLT (Gr 3) }\end{array}$ \\
\hline
\end{tabular}

Figure 3. Association between body composition and hematotoxicity profile. (A) The graph is plotted with the skeletal muscle rate on the vertical axis and the body fat rate on the horizontal axis in patients with pancreatobiliary tract cancer and grade $\geq 2$ hematotoxicity (CTCAE version 4.03 ). The dotted line represents the range of the major population $(70 \%)$ of patients with a decreased WBC count; the gray line represents the scope of the major population of patients with a decreased PLT count; and the circle in bold shows two patients who had decreased WBC and PLT counts. (B) Changes in the body composition and hematotoxicity during pre- and postoperative adjuvant chemotherapy (case from Fig. 1E). Although the body fat rate was dominant preoperatively, the body fat rate markedly decreased postoperatively, changing the adverse events. BMI, body mass index; WBC, white blood cell; PLT, platelet; Gr, grade. 

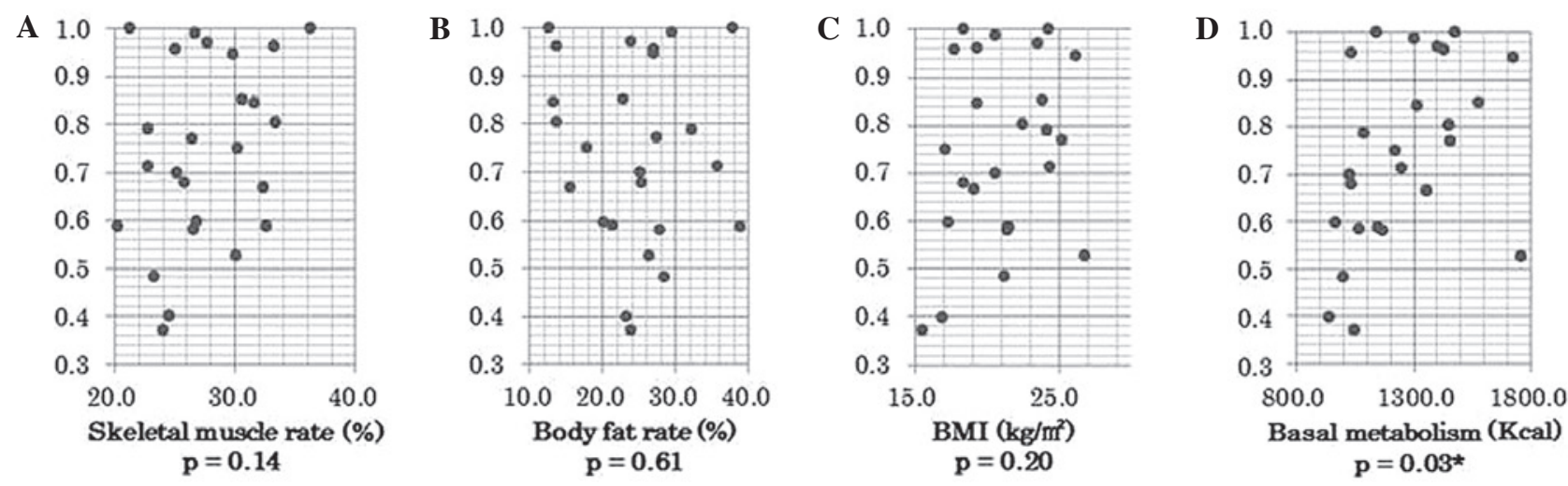

Figure 4. Correlation between the RDI of gemcitabine administration and body composition parameters in patients with pancreatobiliary tract cancer ( $\mathrm{n}=26$ ). (A) RDI and skeletal muscle rate; (B) RDI and body fat rate; (C) RDI and BMI; (D) RDI and basal metabolism. The association with RDI was tested using a Pearson's correlation coefficient test. Only the basal metabolism showed a positive correlation ( $\mathrm{P}=0.029)$. RDI, relative dose intensity; BMI, body mass index.

chemotherapy. All 11 patients with urothelial carcinoma had progressive recurrent cancer. In addition, the age at disease onset and BMI of patients with pancreatobiliary tract cancer and urothelial carcinoma were close to the average for that of the general Japanese population (Table I) (31).

Changes in pathological conditions and body composition over time. Of the 26 patients with pancreatobiliary tract cancer, 14 became unable to continue GEM-based chemotherapy due to progressive disease (PD) or a decreased PS; in these 14 patients, body fat rate had markedly decreased prior to the discontinuation of chemotherapy. Representative changes in body composition over time are presented in Fig. 1A-G. Compared to the start of the GEM administration, there was a statistically significant decrease in the amount of body fat at discontinuation (Figs. 1 and 2A; P=0.01). An increased body weight and skeletal muscle rate were observed in 3 of the 4 patients in whom the chemotherapy was discontinued due to ascites retention associated with the progression of pathological conditions; however, a decrease in body fat rate was observed (Fig. 1F and G). The body fat rate increased along with an improvement in PS and general conditions in 3 patients who had undergone biliary drainage due to the onset of jaundice during chemotherapy (Fig. 1H). Meanwhile, a stable body composition was maintained in 6 of 7 patients with no progression of disease or a complete response/disappearance of the lesion during chemotherapy (Figs. 1I and 2). No significant differences in body composition were observed over time in the control patients with progressive urothelial carcinoma who were similarly treated with GEM-based chemotherapy, despite the progression of pathological conditions (Figs. 1J-K and 2).

Association between body composition and adverse events. The association between grade $\geq 2$ hematotoxicity (CTCAE version 4.03) and body composition was examined in patients with pancreatobiliary tract cancer (Fig. 3). With regard to body composition, the mean body fat and skeletal muscle rates were 25.8 and $26.2 \%$, respectively, in the 14 patients (including 10 female patients) with a decreased white blood cell (WBC) count $\left(<3000 / \mathrm{mm}^{3}\right.$; Fig. $3 \mathrm{~A}$, dotted line); the corresponding rates were 23.3 and $28.7 \%$, respectively, in the 7 patients (including 2 female patients) with a decreased platelet count $\left(<75,000 / \mathrm{mm}^{3}\right.$; Fig. 3A, gray line); and 27.5 and $26.5 \%$, respectively, in 2 patients (including 1 female patient) who had both decreased WBC and platelet counts (Fig. 3A, bold line). Therefore, a decreased WBC count was more common in female patients with a relatively high body fat rate, whereas a decreased platelet count was more common in male patients with a high skeletal muscle rate. Notably, the patient receiving chemotherapy preoperatively and postoperatively exhibited a body weight reduction of $\geq 5 \mathrm{~kg}$ relative to the preoperative weight, which was associated with a marked decrease in the body fat rate from 32.2 to $25.2 \%$, as well as a change in the hematotoxicity profile from a decreased WBC count to a decreased platelet count (Figs. 1E and 3B).

Correlation between body composition and RDI. The association between body composition parameters and the RDI of GEM administration in patients with pancreatobiliary tract cancer was examined. No correlation was identified between RDI and BMI, body fat rate or skeletal muscle rate; however, RDI was found to correlate with basal metabolic rate, with RDI values increasing as the basal metabolic rate increased ( $\mathrm{P}=0.029$; Fig. 4).

\section{Discussion}

Protein and fat are generally broken down in the host as cancers enlarge and progress; at the same time, cytokines and other molecules are released from cancer cells causing cachexia, which results in marked reductions in muscle mass and fat (32-36). When sarcopenia develops along with the progression of cancer lesions, muscle mass decreases first, progressing further into cachexia and accompanied by a decrease in body weight and fat (37-39). However, the present study revealed that the progression of pathological conditions is reflected by decreased body fat in patients with pancreatobiliary tract cancer being treated with GEM-based chemotherapy. As the bile duct and pancreas are deeply involved in the absorption and digestion of fat, we believe that the disintegration of fat associated with cancer progression is observed as a decrease in body fat prior to the development of sarcopenia, accompanied by reduced muscle mass (40). This is consistent with the present findings, as patients intubated with a biliary stent due to the onset of jaundice (Fig. 1H) exhibited an increase in 
body fat rate following the reduction of the jaundice, allowing them to continue the treatment. By contrast, the urinary tract is a retroperitoneal organ with little effect on digestion and absorption, thus causing little change in body composition (41). Therefore, in the case of patients with urothelial carcinoma who were similarly treated with GEM-based chemotherapy, no associations were identified between body fat rates and the progression of pathological conditions or the possibility of continuing chemotherapy (Figs. $1 \mathrm{~J}, 1 \mathrm{~K}$ and 2). In addition, it is notable that, in the patients with pancreatobiliary tract cancer who had ascites retention (Fig. 1F and G), BMI and skeletal muscle mass, estimated using the Omron body composition monitor, increased along with body weight, and only the amount of body fat decreased. It appears that the calculation-based increase in skeletal muscle mass resulted from the principle of the BI method: Fat does not conduct electricity, whereas muscles and moisture do conduct electricity (18). Body weight gain resulting from edema and ascitic fluid makes it very difficult to determine the proper dose of anticancer drugs. Therefore, as the present findings indicate, the measurement of changes in body composition over time with the characteristics of the BI method in consideration may be a useful adjunct index to easily determine pathological conditions.

With regard to the differences in hematotoxicity profile by body composition in patients with pancreatobiliary tract cancer, the current findings indicate that a decreased WBC count was more common in women with a high body fat rate. Similarly, Miura et al (42) have reported that a decreased neutrophil count induced by GEM administration was more common in women. In addition, among the body composition changes associated with surgery in one patient from the present study (Fig. 1E), a marked postoperative reduction in body fat rate resulted in a decreased platelet count (Fig. 3B), suggesting that the hematotoxicity profile may differ according to changes in body composition, as well as to gender. Therefore, it will be necessary to study the association between body composition and changes in the hematotoxicity profile by examining more diseases and regimens (43-45).

Among all body composition parameters investigated in the present study, the RDI associated with GEM administration was found to be positively correlated only with basal metabolism (Fig. 4). Basal metabolism is the basic amount of metabolism required for life maintenance, and the value changes according to the age, height, weight, gender and physical activity levels of individuals $(46,47)$. In this current study, basal metabolism was calculated using our own data and data from the Omron Corporation, which is based on the dietary reference intakes for the Japanese population (31). Approximately $30 \%$ of basal metabolism occurs in the skeletal muscles. In body composition, fat is classified into subcutaneous and visceral fat; the former is needed to maintain energy and body temperature, and the latter is considered to be associated with lifestyle-related diseases such as dyslipidemia and diabetes $(48,49)$. Muscles consist of skeletal muscles, smooth muscles and cardiac muscles, and only skeletal muscles may be increased through exercise. When the skeletal muscle mass decreases, less energy is consumed, resulting in a reduced basal metabolism (19-22,37). The present findings demonstrated that, in patients with pancreatobiliary cancer, there is little change in the skeletal muscle rate compared to the body fat rate. As the basal metabolism was affected by factors such as age and gender differences, an association with RDI was observed. This is not contradictory to the study by Prado et al (43), which reported that doses of 5-fluorouracil correlated with body weight, excluding body fat, in patients with colorectal cancer.

The BI method is easy and safe, and is able to easily measure and monitor changes in a patient's body composition at each visit for chemotherapy. In addition, this method has been reported to correlate extremely well with the evaluation of body composition by computed tomography, magnetic resonance imaging and dual energy X-ray absorptiometry $(15,20-22,50,51)$. The current findings indicate that regularly assessing the body composition, using the BI method, of patients with pancreatobiliary tract cancer receiving GEM-based chemotherapy is a useful adjunct index for understanding pathological conditions and for predicting the continuation of chemotherapy treatment.

In conclusion, measurement of body composition in patients with pancreatobiliary tract cancer over time may be a helpful adjunct index to understand pathological conditions and changes in physical conditions.

\section{References}

1. Burris HA III, Moore MJ, Andersen J, Green MR, Rothenberg ML, Modiano MR, Cripps MC, Portenoy RK, Storniolo AM, Tarassoff P, et al: Improvements in survival and clinical benefit with gemcitabine as first-line therapy for patients with advanced pancreas cancer: A randomized trial. J Clin Oncol 15: 2403-2413, 1997.

2. Moore MJ, Goldstein D, Hamm J, Figer A, Hecht JR, Gallinger S, Au HJ, Murawa P, Walde D, Wolff RA, et al; National Cancer Institute of Canada Clinical Trials Group: Erlotinib plus gemcitabine compared with gemcitabine alone in patients with advanced pancreatic cancer: A phase III trial of the National Cancer Institute of Canada Clinical Trials Group. J Clin Oncol 25: 1960-1966, 2007.

3. Valle J, Wasan H, Palmer DH, Cunningham D, Anthoney A, Maraveyas A, Madhusudan S, Iveson $T$, Hughes $S$, Pereira SP, et al; ABC-02 Trial Investigators: Cisplatin plus gemcitabine versus gemcitabine for biliary tract cancer. N Engl J Med 362: 1273-1281, 2010.

4. Conroy T, Desseigne F, Ychou M, Bouché O, Guimbaud R, Bécouarn Y, Adenis A, Raoul JL, Gourgou-Bourgade S, de la Fouchardière $\mathrm{C}$, et al; Groupe Tumeurs Digestives of Unicancer; PRODIGE Intergroup: FOLFIRINOX versus gemcitabine for metastatic pancreatic cancer. N Engl J Med 364: 1817-1825, 2011.

5. von der Maase H, Sengelov L, Roberts JT, Ricci S, Dogliotti L, Oliver T, Moore MJ, Zimmermann A and Arning M: Long-term survival results of a randomized trial comparing gemcitabine plus cisplatin, with methotrexate, vinblastine, doxorubicin, plus cisplatin in patients with bladder cancer. J Clin Oncol 23: 4602-4608, 2005.

6. Sultana A, Smith CT, Cunningham D, Starling N, Neoptolemos JP and Ghaneh P: Meta-analyses of chemotherapy for locally advanced and metastatic pancreatic cancer. J Clin Oncol 25: 2607-2615, 2007

7. Okusaka T, Ishii H, Funakoshi A, Yamao K, Ohkawa S, Saito S, Saito $\mathrm{H}$ and Tsuyuguchi T: Phase II study of single-agent gemcitabine in patients with advanced biliary tract cancer. Cancer Chemother Pharmacol 57: 647-653, 2006.

8. Ozawa A, Tanji N, Ochi T, Yanagihara Y, Kikugawa T, Yamaguchi A, Ikeda T, Shimamoto K, Aoki K, Toshino A and Yokoyama M: Gemcitabine and cisplatin for advanced urothelial carcinomas: The Ehime University Hospital experience. Int J Clin Oncol 12: 279-283, 2007.

9. Janssen I, Heymsfield SB and Ross R: Low relative skeletal muscle mass (sarcopenia) in older persons is associated with functional impairment and physical disability. J Am Geriatr Soc 50: 889-896, 2002. 
10. Mitsiopoulos N, Baumgartner RN, Heymsfield SB, Lyons W, Gallagher D and Ross R: Cadaver validation of skeletal muscle measurement by magnetic resonance imaging and computerized tomography. J Appl Physiol (1985) 85: 115-122, 1998.

11. Ferland M, Després JP, Tremblay A, Pinault S, Nadeau A, Moorjani S, Lupien PJ, Thériault G and Bouchard C: Assessment of adipose tissue distribution by computed axial tomography in obese women: Association with body density and anthropometric measurements. Br J Nutr 61: 139-148, 1989.

12. Kuk JL, Lee S, Heymsfield SB and Ross R: Waist circumference and abdominal adipose tissue distribution: Influence of age and sex. Am J Clin Nutr 81: 1330-1334, 2005.

13. Nuñez C, Gallagher D, Grammes J, Baumgartner RN, Ross R, Wang Z, Thornton J and Heymsfield SB: Bioimpedance analysis: Potential for measuring lower limb skeletal muscle mass. JPEN J Parenter Enteral Nutr 23: 96-103, 1999.

14. Pietrobelli A, Morini P, Battistini N, Chiumello G, Nuñez C and Heymsfield SB: Appendicular skeletal muscle mass: Prediction from multiple frequency segmental bioimpedance analysis. Eur J Clin Nutr 52: 507-511, 1998.

15. Janssen I, Heymsfield SB, Baumgartner RN and Ross R: Estimation of skeletal muscle mass by bioelectrical impedance analysis. J Appl Physiol (1985) 89: 465-471, 2000.

16. Schwan HP and Kay CF: The conductivity of living tissues. Ann NY Acad Sci 65: 1007-1013, 1957.

17. Oken MM, Creech RH, Tormey DC, Horton J, Davis TE, McFadden ET and Carbone PP: Toxicity and response criteria of the Eastern Cooperative Oncology Group. Am J Clin Oncol 5 : 649-655, 1982

18. Houtkooper LB, Lohman TG, Going SB and Howell WH: Why bioelectrical impedance analysis should be used for estimating adiposity. Am J Clin Nutr 64 (Suppl 3): 436S-448S, 1996.

19. Oshima Y,Shiga T,Namba H and Kuno S: Estimation of whole-body skeletal muscle mass by bioelectrical impedance analysis in the standing position. Obes Res Clin Pract 4: e1-e82, 2010.

20. Oshima Y and Shiga T: Within-day variability of whole-body and segmental bioelectrical impedance in a standing position. Eur J Clin Nutr 60: 938-941, 2006.

21. Ishiguro N, Kanehisa H, Miyatani M, Masuo Y and Fukunaga T: A comparison of three bioelectrical impedance analyses for predicting lean body mass in a population with a large difference in muscularity. Eur J Appl Physiol 94: 25-35, 2005.

22. Tanaka NI, Miyatani M, Masuo Y, Fukunaga T and Kanehisa H: Applicability of a segmental bioelectrical impedance analysis for predicting the whole body skeletal muscle volume. J Appl Physiol 103: 1688-1695, 2007.

23. Kushner RF, Kunigk A, Alspaugh M, Andronis PT, Leitch CA and Schoeller DA: Validation of bioelectrical-impedance analysis as a measurement of change in body composition in obesity. Am J Clin Nutr 52: 219-223, 1990.

24. Deurenberg P, Tagliabue A and Schouten FJ: Multi-frequency impedance for the prediction of extracellular water and total body water. Br J Nutr 73: 349-358, 1995.

25. Stall SH, Ginsberg NS, DeVita MV, Zabetakis PM, Lynn RI, Gleim GW, Wang J, Pierson RN Jr and Michelis MF: Comparison of five body-composition methods in peritoneal dialysis patients. Am J Clin Nutr 64: 125-130, 1996.

26. Gallagher D, Belmonte D, Deurenberg P, Wang Z, Krasnow N, Pi-Sunyer FX and Heymsfield SB: Organ-tissue mass measurement allows modeling of REE and metabolically active tissue mass. Am J Physiol 275: E249-E258, 1998.

27. Bosy-Westphal A, Later W, Hitze B, Sato T, Kossel E, Gluer CC, Heller M and Muller MJ: Accuracy of bioelectrical impedance consumer devices for measurement of body composition in comparison to whole body magnetic resonance imaging and dual X-ray absorptiometry. Obes Facts 1: 319-324, 2008.

28. Kataoka H: A new monitoring method for the estimation of body fluid status by digital weight scale incorporating bioelectrical impedance analyzer in definite heart failure patients. J Card Fail 15: 410-418, 2009.

29. Eisenhauer EA, Therasse P, Bogaerts J, Schwartz LH, Sargent D, Ford R, Dancey J, Arbuck S, Gwyther S, Mooney M, et al: New response evaluation criteria in solid tumours: Revised RECIST guideline (version 1.1). Eur J Cancer 45: 228-247, 2009.

30. Nakajima H, Koizumi K, Tanaka T, Ishigaki Y, Yoshitake $Y$, Yonekura H, Sakuma T, Fukushima T, Umehara H, Ueno S, et al: Loss of HITS (FAM107B) expression in cancers of multiple organs: Tissue microarray analysis. Int J Oncol 41: 1347-1357, 2012.
31. Ministry of Health, Labour and Welfare: Health Japan 21 National Health and Nutrition Survery: http://www.mhlw.go.jp/ seisakunitsuite/bunya/kenkou_iryou/kenkou/kenkounippon21/ en/eiyouchousa/.

32. Fearon K, Arends $\mathrm{J}$ and Baracos V: Understanding the mechanisms and treatment options in cancer cachexia. Nat Rev Clin Oncol 10: 90-99, 2013

33. Nelson KA, Walsh D and Sheehan FA: The cancer anorexia-cachexia syndrome. J Clin Oncol 12: 213-225, 1994.

34. Puccio $\mathrm{M}$ and Nathanson L: The cancer cachexia syndrome. Semin Oncol 24: 277-287, 1997.

35. Parry-Billings M, Leighton B, Dimitriadis GD, Curi R, Bond J, Bevan S, Colquhoun A and Newsholme EA: The effect of tumour bearing on skeletal muscle glutamine metabolism. Int J Biochem 23: 933-937, 1991

36. Cruz-Jentoft AJ, Baeyens JP, Bauer JM, Boirie Y, Cederholm T, Landi F, Martin FC, Michel JP, Rolland Y, Schneider SM, et al: Sarcopenia: European consensus on definition and diagnosis: Report of the European working group on Sarcopenia in older people. Age Ageing 39: 412-423, 2010.

37. Gordon JN, Green SR and Goggin PM: Cancer cachexia. QJM 98: 779-788, 2005.

38. Scott HR, McMillan DC, Forrest LM, Brown DJ, McArdle CS and Milroy R: The systemic inflammatory response, weight loss, performance status and survival in patients with inoperable non-small cell lung cancer. Br J Cancer 87: 264-267, 2002.

39. George J, Cannon T, Lai V, Richey L, Zanation A, Hayes DN, Shores C, Guttridge D and Couch M: Cancer cachexia syndrome in head and neck cancer patients: Part II. Pathophysiology. Head Neck 29: 497-507, 2007.

40. Das SK, Eder S, Schauer S, Diwoky C, Temmel H, Guertl B, Gorkiewicz G, Tamilarasan KP, Kumari P, Trauner M, et al: Adipose triglyceride lipase contributes to cancer-associated cachexia. Science 333: 233-238, 2011.

41. Pelucchi C, Bosetti C, Negri E, Malvezzi M and La Vecchia C: Mechanisms of disease: The epidemiology of bladder cancer. Nat Clin Pract Urol 3: 327-340, 2006.

42. Miura A, Onoue M, Terada K, Takahashi K and Inui K: Gender differences in hematotoxicity induced by gemcitabine monotherapy. Jpn J Pharm Health Care Sci 36: 57-60, 2010.

43. Prado CM, Baracos VE, McCargar LJ, Mourtzakis M, Mulder KE, Reiman T, Butts CA, Scarfe AG and Sawyer MB: Body composition as an independent determinant of 5-fluorouracil-based chemotherapy toxicity. Clin Cancer Res 13: 3264-3268, 2007.

44. Prado CM, Baracos VE, McCargar LJ, Reiman T, Mourtzakis M, Tonkin K, Mackey JR, Koski S, Pituskin E and Sawyer MB: Sarcopenia as a determinant of chemotherapy toxicity and time to tumor progression in metastatic breast cancer patients receiving capecitabine treatment. Clin Cancer Res 15: 2920-2926, 2009.

45. Gusella M, Toso S, Ferrazzi E, Ferrari M and Padrini R: Relationships between body composition parameters and fluorouracil pharmacokinetics. Br J Clin Pharmacol 54: 131-139, 2002.

46. Ganpule AA, Tanaka S, Ishikawa-Takata K and Tabata I Interindividual variability in sleeping metabolic rate in Japanese subjects. Eur J Clin Nutr 61: 1256-1261, 2007.

47. Usui C, Takahashi E, Gando Y, Sanada K, Oka J, Miyachi M, Tabata I and Higuchi M: Relationship between blood adipocytokines and resting energy expenditure in young and elderly women. J Nutr Sci Vitaminol (Tokyo) 53: 529-535, 2007.

48. Wu J, Boström P, Sparks LM, Ye L, Choi JH, Giang AH, Khandekar M, Virtanen KA, Nuutila P, Schaart G, et al: Beige adipocytes are a distinct type of thermogenic fat cell in mouse and human. Cell 150: 366-376, 2012.

49. Cohen P, Levy JD, Zhang Y, Frontini A, Kolodin DP, Svensson KJ, Lo JC, Zeng X, Ye L, Khandekar MJ, et al: Ablation of PRDM16 and beige adipose causes metabolic dysfunction and a subcutaneous to visceral fat switch. Cell 156: 304-316, 2014

50. Ellegård LH, Ahlén M, Körner U, Lundholm KG, Plank LD and Bosaeus IG: Bioelectric impedance spectroscopy underestimates fat-free mass compared to dual energy X-ray absorptiometry in incurable cancer patients. Eur J Clin Nutr 63: 794-801, 2009.

51. Yamakage $H$, Ito $R$, Tochiya $M$, Muranaka $K$, Tanaka $M$, Matsuo Y, Odori S, Kono S, Shimatsu A and Satoh-Asahara N: The utility of dual bioelectrical impedance analysis in detecting intra-abdominal fat area in obese patients during weight reduction therapy in comparison with waist circumference and abdominal CT. Endocr J 61: 807-819, 2014. 